\title{
Starch Crystal Measurement
}

National Cancer Institute

\section{Source}

National Cancer Institute. Starch Crystal Measurement. NCI Thesaurus. Code C81951.

The determination of the amount of starch crystals present in a sample. 